\title{
Respiratory inductive plethysmography accuracy at varying PEEP levels and degrees of acute lung injury
}

\author{
D. G. MARKHORST*†‡, J. P. VAN GESTEL $\ddagger$ H. R. VAN GENDERINGEN $\S$, \\ J. J. HAITSMA $\uparrow$, B. LACHMANN 9 and A. J. VAN VUGHT‡ \\ $\dagger 1$ Pediatric Intensive Care Unit, Vrije Universiteit Medical Center, PO Box 7057, \\ 1007 MB Amsterdam, The Netherlands \\ †Pediatric Intensive Care Unit, University Medical Center Utrecht, Utrecht, The Netherlands. \\ $\S$ Department of Physics and Medical Technology, Vrije Universiteit Medical Center, \\ Amsterdam, The Netherlands \\ qDepartment of Anesthesiology, Erasmus MC-Faculty Rotterdam, \\ Rotterdam, The Netherlands
}

(Received 21 September 2005; in final form 15 December 2005)

\begin{abstract}
Background and objective: This study was performed to assess the accuracy of respiratory inductive plethysmographic (RIP) estimated lung volume changes at varying positive end-expiratory pressures (PEEP) during different degrees of acute respiratory failure. Methods: Measurements of inspiratory tidal volume were validated in eight piglets during constant volume ventilation at incremental and decremental PEEP levels and with increasing severity of pulmonary injury. RIP accuracy was assessed with calibration from the healthy state, from the disease state as the measurement error was assessed, and at various PEEP levels.

Results: Best results (bias 3\%, precision 7\%) were obtained in healthy animals. RIP accuracy decreased with progressing degrees of acute respiratory failure and was PEEP dependent, unless RIP was calibrated again. When calibration was performed in the disease state as the measurement error was assessed, bias was reduced but precision did not improve (bias $-2 \%$, precision $9 \%$ ).

Conclusions: RIP accuracy is within the accuracy range found in monitoring devices currently in clinical use. Most reliable results with RIP are obtained when measurements are preceded by calibration in pulmonary conditions that are comparable to the measurement period. When RIP calibration is not possible, fixed weighting of the RIP signals with species and subject size adequate factors is an alternative. Measurement errors should be taken into account with interpretation of small volume changes.
\end{abstract}

Keywords: Diagnostic techniques, Respiratory system; Lung volume measurements; Respiratory distress syndrome, adult; Respiratory function tests

\section{Introduction}

Mechanical ventilation may lead to ventilator-associated lung injury as a result of alveolar over-distension as well as cyclic re-expansion of alveoli collapsed during expiration $[1-4]$. Both experimental and clinical data suggest that mechanical ventilation that optimizes lung volume can diminish the deleterious effects of mechanical ventilation $[5,6]$.

A serious deficiency in current routine monitoring of patients receiving mechanical ventilation is the lack of simple, reliable and practical methods that can be used to measure mean lung volume (changes) during ventilation. Respiratory inductive plethysmography (RIP)

*Corresponding author. E-mail: dg.markhorst@vumc.nl

Journal of Medical Engineering \& Technology 
is a non-invasive monitoring technique, which is able to monitor and measure lung volume changes.

RIP is based on the principle that the chest wall has two compartments, the rib cage and abdomen. Each compartment is associated with a single motion variable that can be measured with external sensors, and the sum of both variables can be calibrated against a known volume change to provide volumetric measurements. RIP generates dimensionless counts that can be calibrated to volume using the qualitative diagnostic calibration (QDC) algorithm [7] or the least mean squares technique [8]. RIP can be used to monitor tidal volume (VT) [9] and changes in endexpiratory lung volume ( $\triangle$ EELV) [10]. RIP has also been used to assess mean lung volume induced by the mean airway pressure during high-frequency oscillatory ventilation (HFOV) and may provide a clinical useful tool, provided its accuracy with changing airway can be established [11].

Linearity of RIP with insufflated volume has been validated [10,12-14], although some have reported a limited precision of the method [15]. We studied the accuracy of RIP during conventional mechanical ventilation (CMV) to assess whether this accuracy depended on PEEP level or disease.

\section{Materials and methods}

\subsection{Animal preparation}

The experiments were performed at the anaesthesiology department, Erasmus MC-Faculty Rotterdam; the study was approved by the local Animal Committee of the Erasmus University Rotterdam. Anaesthesia was induced in eight female Yorkshire pigs (weight $20 \pm 1 \mathrm{~kg}$ ) with $10 \mathrm{mg} \mathrm{kg}^{-1}$ ketamine (Ketalin $100 \mathrm{mg} \mathrm{ml}^{-1}$, Apharmo, Arnhem, the Netherlands) and $0.5 \mathrm{mg} \mathrm{kg}^{-1}$ midazolam (Dormicum $5.0 \mathrm{mg} \mathrm{ml}^{-1}$, Roche Ned., Mijdrecht, the Netherlands) intramuscularly. After obtaining intravenous access a loading dose of $35 \mu \mathrm{g} \mathrm{kg}^{-1}$ fentanyl $(0.05 \mathrm{mg}$ $\mathrm{ml}^{-1}$, B. Braun Melsungen AG, Melsungen, Germany) was given and continuous infusion of fentanyl $\left(35 \mu \mathrm{g} \mathrm{kg}^{-1} \mathrm{~h}^{-1}\right)$ and midazolam $\left(9 \mu \mathrm{g} \mathrm{kg} \mathrm{gin}^{-1}\right)$ was started. After placing an 8-mm endotracheal tube via a tracheotomy, the animals were ventilated (AVEA, Viasys Healthcare, Palm Springs, CA) in volume controlled mode (VC) with the following settings: frequency $20 / \mathrm{min}$, positive endexpiratory pressure (PEEP) $5 \mathrm{~cm} \mathrm{H}_{2} \mathrm{O}$, inpiratory time $0.8 \mathrm{~s}$ $(25 \%)$, inspiratory pause time $0.3 \mathrm{~s}(10 \%)$ and $100 \%$ oxygen. Minute ventilation was set to deliver an inspiratory tidal volume $\left(V_{\mathrm{T}_{\mathrm{i}}}\right)$ of $10 \mathrm{ml} \mathrm{kg} \mathrm{kg}^{-1}$. Inspiratory gas was humidified with a hygrophobe heat and moisture exchanger ('Sterivent S' Mallinckrodt, Mirandola, Italy). Muscle relaxation was achieved by continuous infusion of $2.5 \mu \mathrm{g}$ $\mathrm{kg}^{-1} \min ^{-1}$ pancuronium bromide (Pavulon; Organon Technika, Boxtel, The Netherlands).
Subsequently, the carotid artery was cannulated to obtain arterial blood pressures. A blood gas-monitoring sensor (Paratrend 7+/Trendcare, Diametrics Medical Ltd, High Wycombe, UK) was inserted into the right femoral artery to continuously analyse blood gases and $\mathrm{pH}$. The right internal jugular vein was cannulated and a 5 Fr pulmonary artery catheter was introduced (TD catheter 4 lumen; Arrow Holland medical products, Houten, The Netherlands). The bladder was catheterized through the abdominal wall. Temperature was kept in the normal range by a heating pad. On completion of the experiments, the animals were killed with an overdose of pentobarbital.

\subsection{Measurements}

Haemodynamic and respiratory baseline measurements were performed prior to lung lavage and following stabilization after surgery (prelavage measurements). Respiratory system compliance was derived according to $C_{\mathrm{rs}}=V_{\mathrm{T}_{\mathrm{i}}} /\left(P_{\text {plat }}-\mathrm{PEEP}\right)$, with $V_{\mathrm{T}_{\mathrm{i}}}$ being inspiratory tidal volume and $P_{\text {plat }}$ the plateau pressure.

A system for integrated measurement of ventilator settings and dependent physiological variables as described in detail previously was used [16]. In short, pressure at the airway opening was measured at the Y-piece of the ventilator (143PC05D differential pressure transducer, Honeywell, Freeport, IL). Inspiratory and expiratory flow were measured continuously at the airway opening using a flow probe (AVEA, Viasys Healthcare, Palm Springs, CA) and integrated to a volume signal ( $\left.V_{\text {vent }}\right)$ [17]. Lung volume changes were derived from RIP. The thoracic belt was placed $4 \mathrm{~cm}$ above the xiphoid processus, the abdominal belt $4 \mathrm{~cm}$ above the umbilicus. Both belts (characterized by minimal mechanical impedance) were then secured by stitches and the position of the belts was checked at the end of experiments. The dimensionless counts of the abdominal $\left(\mathrm{RIP}_{\mathrm{abd}}\right)$ and ribcage $\left(\mathrm{RIP}_{\mathrm{rc}}\right)$ belts, airway pressure and $V_{\text {vent }}$ were sampled at $140 \mathrm{~Hz}$ and stored for offline analysis [16].

\subsection{Experimental procedure}

2.3.1. Reference measurements. Following stabilization after instrumentation, respiratory variables $\left(P_{\text {aw }}, V_{\text {vent }}\right.$, $\mathrm{RIP}_{\mathrm{abd}}$ and $\mathrm{RIP}_{\mathrm{rc}}$ ) were recorded during a 5-minute period of uninterrupted mechanical ventilation (HEALTHYQDC). These signals were used for calibration of the RIP, using the QDC algorithm.

Then, the animals were ventilated with constant $V_{\mathrm{T}_{\mathrm{i}}}$ and PEEP increasing from 5 to $20 \mathrm{~cm} \mathrm{H}_{2} \mathrm{O}$, with $5 \mathrm{~cm} \mathrm{H}_{2} \mathrm{O}$ increments. This was followed by PEEP decrements of $5 \mathrm{~cm}$ $\mathrm{H}_{2} \mathrm{O}$ down to $5 \mathrm{~cm} \mathrm{H}_{2} \mathrm{O}$ (HEALTHY) (figure 1). Time between PEEP changes was 5 minutes. Prior to PEEP change, physiologic variables were noted. 

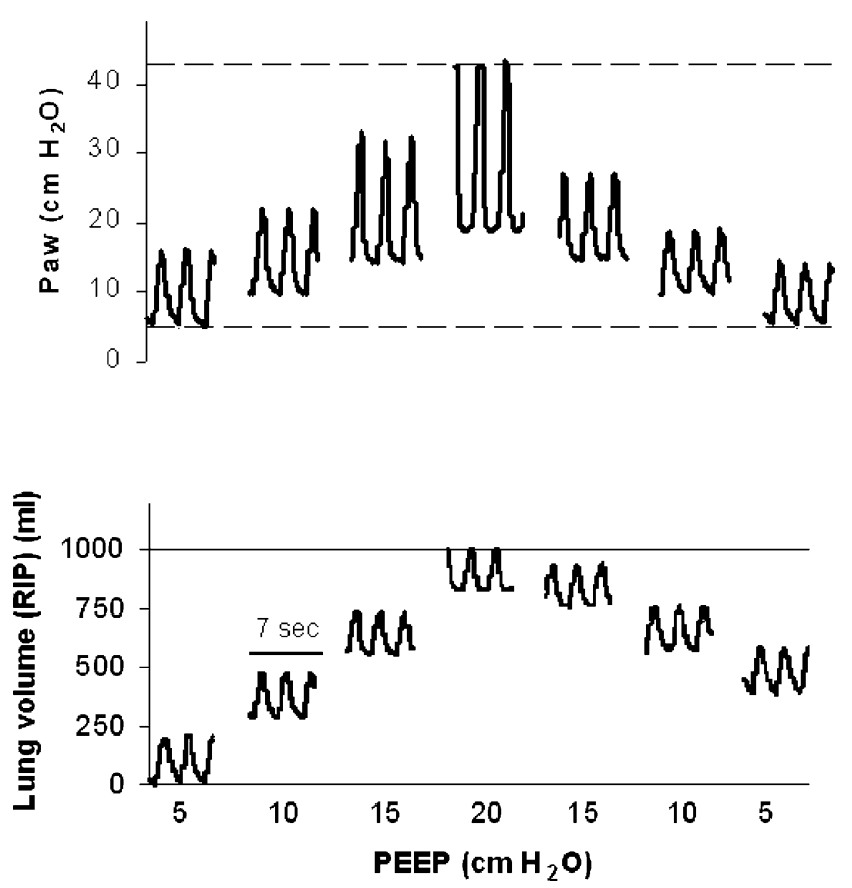

Figure 1. Representative data record showing physiologic data (Airway pressure $\left(P_{\mathrm{aw}}\right)$ and calibrated RIP volume signal) during a PEEP sequence in a healthy piglet. Signals are presented as 7-s snapshots per step and plotted as a function of time, with each PEEP step labelled on the horizontal axis.

Subsequently, moderate lung injury was induced with a single lung lavage with $50 \mathrm{ml} \mathrm{kg}^{-1}$ warmed saline [18]. To avoid development of respiratory acidosis, $V_{\mathrm{T}_{\mathrm{i}}}$ was temporarily increased to maintain $\mathrm{PaCO}_{2}$ below $65 \mathrm{mmHg}$. Following a 30-minute stabilization period, physiologic variables were noted $(L A V I)$, and incremental and decremental PEEP steps were applied again at the initial $V_{\mathrm{T}_{\mathrm{i}}}$ setting.

Acute lung injury $(A L I)$ was induced by repeated lung lavages with $50 \mathrm{ml} \mathrm{kg}^{-1}$ warmed saline until $\mathrm{PaO}_{2}$ was persistently below $80 \mathrm{mmHg}$ at $5 \mathrm{~cm} \mathrm{H} \mathrm{H}_{2} \mathrm{O}$ PEEP, $\mathrm{FiO}_{2}$ of 1.0 and a tidal volume of $10 \mathrm{ml} \mathrm{kg}^{-1}$ [18]. After the last lavage, the ventilator settings remained unchanged for one hour. If $\mathrm{PaO}_{2}$ increased to values above $100 \mathrm{mmHg}$, lavages were repeated and stabilization time reset. Thereafter, the lungs are assumed to be injured and atelectatic [18]. Following stabilization at lavage target, measurements were repeated (lavage target measurements). Subsequently, PEEP was increased stepwise until $P_{\text {plat }}$ reached $50 \mathrm{~cm} \mathrm{H}_{2} \mathrm{O}$ and stepwise decreased to baseline.

Ventilator-induced lung injury (VILI) was induced by ventilation with zero PEEP and $V_{\mathrm{T}_{\mathrm{i}}}$ set to obtain $P_{\text {plat }}$ of $50 \mathrm{~cm} \mathrm{H}_{2} \mathrm{O}$ [19]. These settings were maintained for 60 minutes. Physiologic measurements and incremental and decremental PEEP steps were repeated (VILI). At the end of the experiment, PEEP was reduced to $5 \mathrm{~cm} \mathrm{H}_{2} \mathrm{O}$ and physiologic variables were recorded after a stabilisation period (end experiment).

\subsection{Data processing}

2.4.1. Determination of $V \mathbf{T}_{\mathbf{i}} \cdot V_{\mathrm{T}_{\mathrm{i}}}$ delivered by the ventilator $\left(V_{\mathrm{T}_{\mathrm{i}, \mathrm{VENT}}}\right)$ was determined from the $V_{\text {vent }}$ signal as the difference between end-inspiratory and the preceding endexpiratory value. The same algorithm was used to determine inspiratory amplitudes of RIP $_{a b d}$, RIP $_{r c}$ and the summed RIP signals.

2.4.2. Calibration of RIP signals. To calibrate RIP to volume $(\Delta V)$ above functional residual capacity (FRC), the QDC procedure was performed as described by Sackner et al. [7]. The method uses the equation $\Delta V=M(K \times$ $\left.\Delta \mathrm{RIP}_{\mathrm{rc}}+\Delta \mathrm{RIP}_{\mathrm{ab}}\right)$, in which $\Delta \mathrm{RIP}_{\mathrm{rc}}$ and $\Delta \mathrm{RIP}_{\mathrm{ab}}$ are the rib cage and abdominal RIP changes relative to the values at end-expiratory lung volume, respectively. $K$ is a calibration factor, indicating the relative contribution of both compartments to volume, and $M$ scales the sum to volume and is expressed in $\mathrm{ml}$. To perform the QDC, a number of undisturbed breaths were collected during 5 minutes of ventilation. Breaths with similar tidal volume were selected, based on the uncalibrated sum signal $\left(\operatorname{RIP}_{\mathrm{rc}}+\mathrm{RIP}_{\mathrm{ab}}\right)$, including only breaths within one standard deviation (SD) of the mean. Then, the SDs of RIP $_{r c}$ and RIP ab $_{\text {were }}$ determined over the selected breaths. Calibration factor $K$ was estimated by $\mathrm{SD}\left(\mathrm{RIP}_{\mathrm{ab}}\right) / \mathrm{SD}\left(\mathrm{RIP}_{\mathrm{rc}}\right) . M$ was calculated

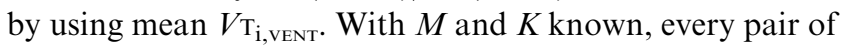
RIP $_{\mathrm{ab}}$ and RIP $_{\mathrm{rc}}$ was converted to a calibrated volume.

To assess the validity of RIP at various end-expiratory lung volumes and in various disease states, RIP was calibrated using QDC on the HEALTHYQDC signals. Inspiratory tidal volume measured with RIP ( $\left.V_{\mathrm{T}_{\mathrm{i}, \mathrm{RIP}}}\right)$ per PEEP step was calculated, using the obtained QDC calibration factor. To assess the influence of factor $K$, we also used $K=0$ (abdominal band only), $K=1$ (weighing ribcage and abdominal band equally) and $K=\infty$ (ribcage band only), as well as values that have been used in other studies of 0.5 [20] and 2.0 [21]. These values were compared with concomitant $V_{\mathrm{T}_{\mathrm{i}, \mathrm{VENT}}}$. This procedure was performed for each disease state (HEALTHY,LAVI, ALI, VILI) and for each PEEP step.

Next, to investigate the influence of end-expiratory lung volume on the validity of QDC, RIP was calibrated at each PEEP step in HEALTHY. $V_{\mathrm{T}_{\mathrm{i}, \mathrm{RIP}}}$ was compared with concomitant $V_{\mathrm{T}_{\mathrm{i} \text { VENT }}}$ for each PEEP step (excluding values used for calibration). To investigate QDC validity in different disease states, $V_{\mathrm{T}_{\mathrm{i}, \mathrm{RIP}}}$ was calculated for each PEEP step, with QDC calibration factors $M$ and $K$ obtained at PEEP of 10 (incremental PEEP), 20 and 10 (decremental PEEP) $\mathrm{cm} \mathrm{H}_{2} \mathrm{O}$. This procedure was performed for each disease state (HEALTHY, LAV1, ALI, VILI). 
2.4.3. Statistical analysis. Data are represented as mean \pm SD. Intragroup comparisons were evaluated using a two-way analysis of variance for repeated measurements (ANOVA). $V_{\mathrm{T}_{\mathrm{i} \text { RIP }}}$ was compared with $V_{\mathrm{T}_{\mathrm{i}, \mathrm{VENT}}}$ by means of Bland-Altman analysis [22]. Bias is expressed as the per cent error between both measurements $\left(V_{\mathrm{T}_{\mathrm{i}, \mathrm{VENT}}}-V_{\mathrm{T}_{\mathrm{i}, \mathrm{RIP}}}\right)$ $\left.V_{\mathrm{T}_{\mathrm{i}, \mathrm{VENT}}}\right)$, and precision is expressed as two standard deviations (2SD) of the relative differences. Root mean square error (RMSE) was used as a measure of accuracy. Differences in precision between measurements were assessed with Friedman's nonparametric two-way analysis of variance. A $p$ value less than 0.05 was considered significant.

\section{Results}

Data could be obtained in eight piglets in disease states state HEALTHY, LAVI and ALI. During infliction of VILI one animal died and two developed a pneumothorax. In one animal oxygenation did not significantly decrease during the induction of VILI $\left(\mathrm{PaO}_{2} 286 \mathrm{mmHg}\right.$ after 60 minutes). The results of these four animals were excluded from analysis of VILI and end experiment data. Induction of VILI had to be terminated in the four remaining animals before 60 minutes as a result of decreasing $\mathrm{PaO}_{2}$ of $39 \pm 15 \mathrm{mmHg}$ at zero PEEP. Analysis of VILI measurements is based on measurements in these four animals.

Physiologic variables describing each disease state at baseline measurements are given in table 1. $C_{\mathrm{rs}}$ decreased significantly as a result of lavages. Following the first lavage, $\mathrm{PaO}_{2} / \mathrm{FiO}_{2}$ was below $400 \mathrm{mmHg}$ and significantly decreased with further lavages. At VILI, $\mathrm{PaO}_{2} / \mathrm{FiO}_{2}$ was lower than the values at $A L I$.

Figure 1 shows representative example of the PEEP sequence. With subsequent PEEP steps, $V_{\mathrm{T}_{\mathrm{i} \text {,VENT }}}$ remained constant. At high PEEP levels in the healthy animal, pressure amplitude $\left(P_{\text {plat }}-\right.$ PEEP) increased. Grouped data from a PEEP sequence in healthy animals are shown in figure 2; incremental PEEP steps are shown in the left panels, and decremental PEEP steps in the right panels. Hysteresis of end-expiratory lung volume is shown in figure 2; at identical PEEP levels, RIP estimated end-expiratory volume is lower during incremental PEEP steps (figure 2 (a)) compared to decremental PEEP (figure 2

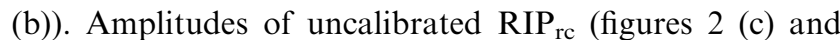
(d)) and RIP abd signals (figures 2 (e) and (f)) and tidal volumes (figures 2 (i) and (j)) measured from the calibrated RIP signals changed with changing PEEP. RIP rc $_{\text {ampli- }}$ tudes were lower during decremental PEEP than during incremental PEEP $(p<0.05), \operatorname{RIP}_{\text {abd }}$ amplitudes at 10 and $15 \mathrm{~cm} \mathrm{H}_{2} \mathrm{O}$ decremental PEEP were higher than they were at equivalent values incremental $(p<0.05)$. RIP amplitude change also displayed hysteresis. There was no relation between RIP amplitude change of either band and summed end-expiratory uncalibrated RIP counts or respiratory system compliance $\left(\mathrm{C}_{\mathrm{rs}}\right)$ (figures $2(\mathrm{~g})$ and $(\mathrm{h})$ ). The relative RIP measurement error, expressed as $\left(V_{\mathrm{T}_{\mathrm{i}, \text { vent }}}-V_{\mathrm{T}_{\mathrm{i}, \mathrm{RIP}}}\right) /$ $V \mathrm{~T}_{\mathrm{i}, \mathrm{vent}}$ was not related to PEEP, but measurement standard deviation increased with increasing PEEP.

Both changes in PEEP and health state independently and significantly influenced measurement accuracy.

Table 2 lists the RIP measurement errors after QDC calibration in the healthy animal. The influence of increasing lung injury and influence of fixed weight factor $K$ on bias and precision was evaluated. Best results, bias and precision (defined as 2SD interval) $<10 \%$, were obtained in the healthy animal, whereas the error increased with progressing disease severity $(p<0.05)$.

The use of $K=1$ did not influence the measurement error compared to the use of calibration factors obtained with QDC in the healthy state. With $K=0$ bias was reduced $(p<0.05)$ but precision was poorer $(p<0.05)$ whereas $K=\infty$ resulted in both increased bias and poorer precision $(p<0.05$, changes in bias in healthy animals however did not reach statistical significance) (table 2). In all diseased animals, precision with fixed $K=0$ or infinite was poorer than with either QDC derived calibration or fixed $K=1$ $(p<0.05)$.

When QDC was performed in the same disease state as the measurement error was assessed (table 3), we found a reduction in bias $(p<0.05)$ but not in precision at PEEP 20 and $10 \mathrm{~cm} \mathrm{H}_{2} \mathrm{O}$ decremental. There was no significant improvement of either bias or precision with calibration at PEEP $10 \mathrm{~cm} \mathrm{H}_{2} \mathrm{O}$ incremental in the diseased states when

Table 1. Ventilatory and blood gas values at baseline $\left(\mathrm{PEEP}=5 \mathrm{~cm} \mathrm{H} \mathrm{H}_{2} \mathrm{O}\right)$, except at VILI where measurements were obtained at the lowest PEEP with target $\mathrm{PaO} 2$ of $50 \mathrm{mmHg}$.

\begin{tabular}{|c|c|c|c|c|c|}
\hline & $\begin{array}{c}\text { Prelavage } \\
\text { (healthy) } \\
(n=8)\end{array}$ & $\begin{array}{c}\text { Following } \\
\text { one lavage } \\
(n=8)\end{array}$ & $\begin{array}{c}\text { At lavage } \\
\text { target } \\
(n=8)\end{array}$ & $\begin{array}{l}\text { At VILI } \\
\text { target } \\
(n=4)\end{array}$ & $\begin{array}{c}\text { End } \\
\text { experiment } \\
(n=4)\end{array}$ \\
\hline$V_{\mathrm{Ti}}\left(\mathrm{ml} \mathrm{kg}^{-1}\right)$ & $10(1)$ & $12(1)^{\dagger}$ & $12(1)^{\dagger}$ & $12(1)$ & $13(1)$ \\
\hline$C_{\mathrm{rs}}\left(\mathrm{ml} \mathrm{cm} \mathrm{H} \mathrm{O}^{-1} \mathrm{~kg}^{-1}\right)$ & $0.75(0.14)$ & $0.58(0.13)^{\dagger}$ & $0.4(0.08)^{\dagger+}$ & $0.35(0.07)^{\dagger+}$ & $0.39(0.06)^{\dagger !}$ \\
\hline $\mathrm{PaO}_{2}(\mathrm{mmHg})$ & $532(51)$ & $321(101)^{\dagger}$ & $61(12)^{\dagger+}$ & $40(9)^{\dagger \dagger \delta}$ & $43(5)^{\dagger \dagger \delta}$ \\
\hline $\mathrm{PaCO}_{2}(\mathrm{mmHg})$ & $52(6)$ & $61(3)^{\dagger}$ & $61(5)^{\dagger}$ & $47(7)^{8}$ & $64(6)^{\dagger}$ \\
\hline
\end{tabular}

${ }^{\dagger} p<0.05$ compared with healthy, ${ }^{\dagger} p<0.05$ compared with one lavage, ${ }^{\S} p<0.05$ compared with lavage target. 

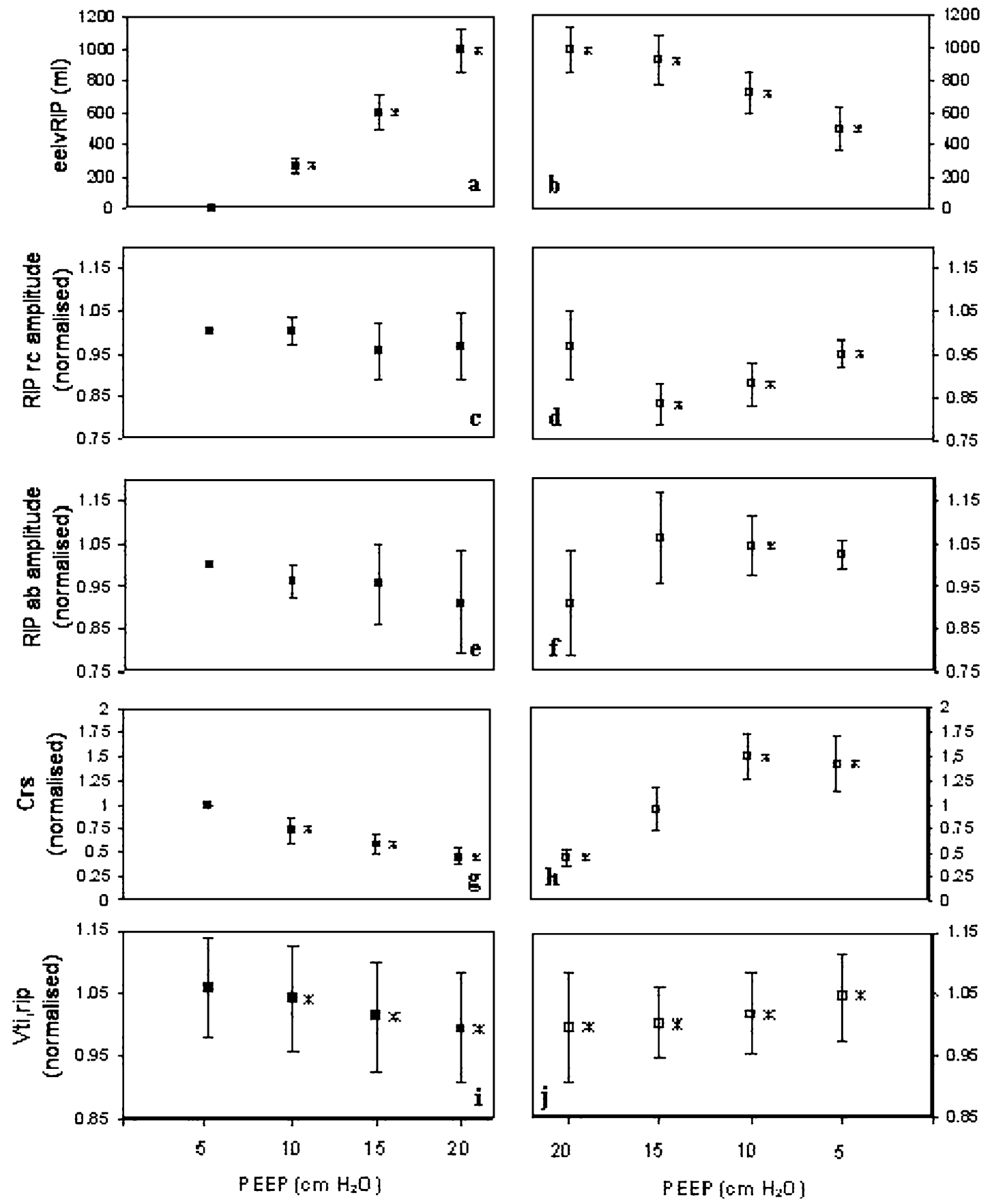

Figure 2. Grouped data from a PEEP sequence in healthy animals. Values are normalized to the initial value at PEEP $=5 \mathrm{~cm}$ $\mathrm{H}_{2} \mathrm{O}$ (incremental). Decremental PEEP steps are plotted in reverse order. *: Significant difference from value obtained at $5 \mathrm{~cm} \mathrm{H}_{2} \mathrm{O}$ incremental PEEP, $p<0.05$; EELV: end expiratory lung volume; RIP $\mathrm{rc}_{\mathrm{rc}}$ and $\mathrm{RIP}_{\mathrm{ab}}$ amplitude: chestwall and abdominal displacement measured with respiratory inductive plethysmography; $C_{\mathrm{rs}}$ : respiratory system compliance; $V_{\mathrm{T}}$,rip: respiratory inductive plethysmography estimated tidal volume.

compared to results with calibration obtained in the HEALTHY state. Figure 3 illustrates the dependence of accuracy on $K$. In the HEALTHY animals (figure 3 (A)) maximal accuracy with fixed $K$ was found with $\mathrm{K}=1$. Accuracy was slightly higher when individual QDC calibration was performed in the healthy state. Accuracy remained within $10 \%$ of maximal accuracy with fixed $K$ between 0.5 and 1.8. In the $A L I$ animals RIP accuracy with fixed $K$ was significantly reduced (figure 3 (B)). Here, accuracy remained within $10 \%$ of maximal accuracy with 
Table 2. Measurement error as quantified by the bias (precision) of respiratory inductive plethysmographic inspiratory tidal volume measurement, at various PEEP levels and in multiple disease states. Calibration using HEALTHYQDC signals. $K=0$ : chest wall belt changes ignored, $K=1$ : weighing ribcage and abdominal belt equally, $K=\infty$ : abdominal belt changes ignored.

\begin{tabular}{|c|c|c|c|c|c|c|}
\hline & QDC & $\mathrm{K}=0$ & $\mathrm{~K}=0.5$ & $\mathrm{~K}=1$ & $\mathrm{~K}=2$ & $\mathrm{~K}=\infty$ \\
\hline Healthy & $3(7)$ & $0(18)^{\S}$ & $2(11)^{\S}$ & $3(7)$ & $3(10)^{\S}$ & $4(15)^{\S}$ \\
\hline Following 1 lavage & $5(10)^{\dagger}$ & $-2(23)^{+\delta}$ & $2(14)^{+5}$ & $5(10)^{\dagger+\delta}$ & $7(13)^{\dagger}$ & $11(24)^{* 5}$ \\
\hline At lavage target & $8(11)$ & $0(25)^{+5}$ & $4(14)^{+5}$ & $8(12)^{\S}$ & $10(16)^{\dagger \S}$ & $13(30)^{\S}$ \\
\hline VILI $(n=4)$ & $11(11)^{\dagger}$ & $0(16)^{+}$ & $9(10)^{\dagger \dagger}$ & $10(10)^{\dagger}$ & $14(13)^{\dagger \S}$ & $18(18)^{\dagger \S}$ \\
\hline Overall & $6(12)^{\dagger}$ & $0(21)^{+5}$ & $4(14)^{+\delta}$ & $6(11)^{\dagger \S}$ & $8(15)^{\dagger+\delta}$ & $11(25)^{\dagger \dagger}$ \\
\hline
\end{tabular}

${ }^{\dagger}$ Significant difference in bias when compared to values derived during health, using identical calibration $(p<0.05)$, ${ }^{\star}$ Significant difference in bias when compared to QDC derived values, ${ }^{\S}$ Significant difference in precision compared with QDC derived values in health $(\mathrm{p}<0.05)$.

Table 3. Measurement error as quantified by the bias (precision) of respiratory inductive plethysmograpic inspiratory tidal volume measurement, at various PEEP levels and in multiple disease states. QDC calibration at PEEP of 10 (incremental PEEP), 20 and 10 (decremental PEEP) $\mathrm{cm} \mathrm{H}_{2} \mathrm{O}$, respectively. Data used for calibration were excluded from analysis of precision and accuracy.

\begin{tabular}{lccc}
\hline & $\begin{array}{c}\text { QDC on } \\
\text { PEEP 10 } \\
\text { (incremental) } \\
\text { Bias (2SD) } \%\end{array}$ & $\begin{array}{c}\text { QDC on } \\
\text { PEEP 20 } \\
\text { (decremental) } \\
\text { Bias (2SD) } \%\end{array}$ & $\begin{array}{c}\text { QDC on } \\
\text { PEEP 10 } \\
\text { (decremental) } \\
\text { Bias (2SD) \% }\end{array}$ \\
\hline $\begin{array}{l}\text { Healthy } \\
\text { Following }\end{array}$ & $2(8)$ & $-4(9)^{\dagger}$ & $-3(8)^{\dagger}$ \\
$\quad$ one lavage & $2(9)$ & $0(9)$ & $-1(9)$ \\
At lavage target & $1(11)$ & $-1(10)^{\dagger}$ & $1(14)^{\dagger}$ \\
VILI $(n=4)$ & $3(11)$ & $-2(8)^{\dagger}$ & $-3(13)$ \\
Overall & $2(10)$ & $-2(9)^{\dagger}$ & $-1(12)^{\dagger}$ \\
\hline
\end{tabular}

${ }^{\dagger}$ Significant difference in bias when compared to HEALTHYQDC derived QDC values $(p<0.05)$.

fixed $K$ between 0.3 and 0.9 . In this range of fixed $K$, accuracy was higher than with $K$ derived from individual QDC calibration performed in the healthy state. QDC calibration performed in the same disease state as the measurement error was assessed, yielded higher accuracy than could be reached with fixed $K$. $K$ and $M$, obtained during QDC at different levels of PEEP, were not PEEP dependent (table 4).

\section{Discussion}

This study assessed the validity of estimation of lung volume changes by respiratory inductive plethysmography during conventional mechanical ventilation at changing PEEP levels and at progressive degrees of acute respiratory failure in animals. A major finding of the present study was a decreasing accuracy of RIP-estimated lung volume changes with progressing degrees of acute respiratory failure, unless RIP was calibrated again. Best accuracy was obtained when calibration weight factor $K$ was determined using QDC. The obtained results were in line with other studies [12,23], but we obtained better precision than earlier investigators did using older versions of the RIP hardware [15,24].

Our study is subject to some limitations. First, the sample size was small. Since only eight piglets were included, the study may have been underpowered, especially with measurements in the VILI state. Second, since a whole body plethysmograph was not available in our laboratory, as a gold standard measurement of lung volume changes we used tidal volumes obtained from integration of flow probe signals. Third, the study was performed in a piglet model rather than in human patients. Due to differences in thoraco-abdominal partitioning with humans, this probably has implications for our findings regarding the accuracy use of a fixed $K=0$ value, this is discussed in more detail further on.

Optimal results (minimal bias) of RIP-estimated volume changes were obtained when calibration was performed in a representative pulmonary condition, e.g. the disease state the animal was in, and above the minimal end-expiratory lung volume. As a consequence, RIP accuracy decreases when pulmonary conditions change significantly, e.g. with deterioration or improvement of the disease. Thus, RIP should not be used to monitor long-term changes. When these conditions can be met, measurement error is within a range of about $\pm 10 \%$. For purposes of clinical monitoring during relatively short procedures, such as lung volume recruitment and subsequent titrating of volume or compliance targeted ventilation, this may be acceptable (even though the accuracy is limited) given the ease of use of RIP, the fact that measurement does not interfere with treatment, and the ability to measure tidal volumes as well as end-expiratory lung volume changes. RIP accuracy is within the accuracy range found in monitoring devices currently in clinical use (table 5), and its use provides additional information. PEEPinduced lung volume recruitment and compliance change in a surfactant-depleted piglet is shown in figure 4 as an example. This could possibly alleviate the need for partitioning respiratory mechanics to differentiate between acute respiratory distress syndrome caused by pulmonary and extrapulmonary disease [25]. 

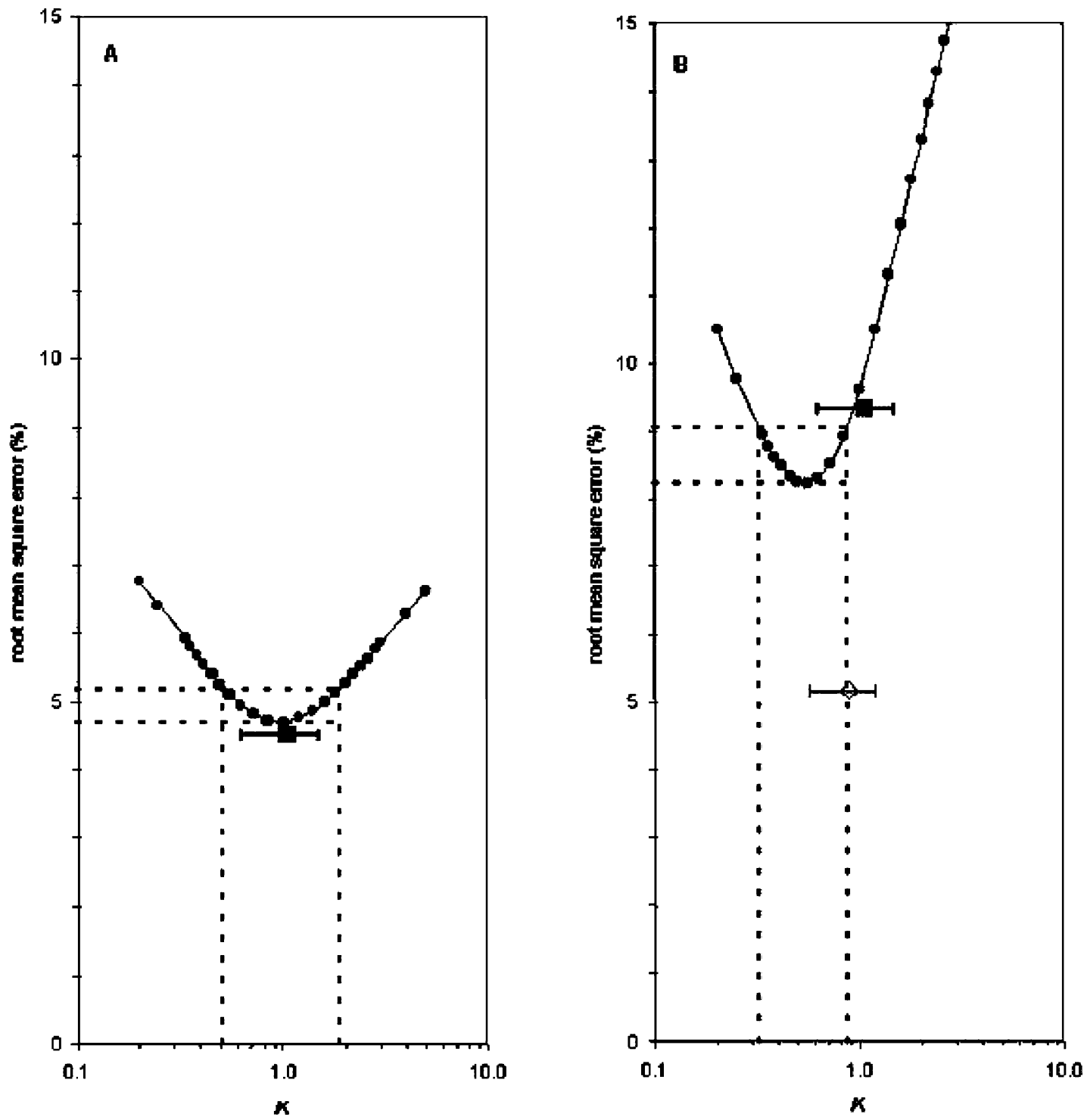

Figure 3. Measurement error (dots), expressed as root mean square error, with changing weight factor $K$ in healthy animals (A) and animals at lavage target (B). Solid squares represent error obtained with calibration factors obtained from individual calibration in healthy animals (HEALTHYQDC), open diamond represents error obtained with calibration factors from individual calibration at $\mathrm{PEEP}=20 \mathrm{~cm} \mathrm{H} \mathrm{H}_{2} \mathrm{O}$ in lavaged animals. Dotted lines represent boundaries of minimal error $\pm 10 \%$. Note logarithmic scale on horizontal axis.

Omitting QDC and assuming a fixed weight factor $K$ would facilitate clinical RIP application, especially during none conventional ventilation modes such as HFOV, where measurement of lung volume is cumbersome. Weighing both signals equally did not influence bias or precision compared with the use of calibration factors obtained in healthy animals. This suggests that QDC is valid during mechanical ventilation, but is not mandatory. Calibration of the dimensionless RIP counts to a known volume is, however, still needed to obtain a calibrated volume. Equal weighing of the signals in our piglet model was adequate, as was found by others using RIP in piglets [11]. In other species this may not be the case, due to anatomic or physiologic differences. In spontaneous breathing healthy infants a $K$ of $0.5-1.0$ has been found adequate [20,12] whereas in healthy adults a $K$ of 2.0 was found [21]. If knowledge of relative rather than absolute changes in lung volume is of interest, the use of uncalibrated summed RIP signals may be sufficient $[11,26]$. However, we have shown that RIP accuracy is $K$-dependent and in our experiments optimal $K$ decreased with increasing lung injury (figure 3 ). The calibration factor $K$ can be regarded as an approximation of 
the absolute slope of the line through the thoracic and abdominal displacements plotted in a Konno-Mead diagram, and thus represents thoraco-abdominal partitioning. This relation depends on anatomical relations and may vary with changes in respiratory mechanics [27].

Underestimation of $V_{\mathrm{T}_{\mathrm{i}, \mathrm{VENT}}}$ by $V_{\mathrm{T}_{\mathrm{i}, \mathrm{RIP}}}$ may in part be explained by the volume reduction when gas is compressed - the isovolumetric pressure change of the lung, sometimes referred to as compressible volume of the lung. When a given volume is inflated in a container with infinite compliance and zero volume, the volume change of the container will be the inflated volume. At the other extreme, when the same volume is injected into a container with infinite pressure and low compliance, the volume change will be negligible. We did not measure functional residual capacity (FRC). Using FRC measured by others in piglets following pulmonary lavage [28] we calculated a compressible volume of $7 \%$ in a lavage target animal at PEEP $5 \mathrm{~cm}$ $\mathrm{H}_{2} \mathrm{O}$ up to $30 \%$ at a PEEP of $25 \mathrm{~cm} \mathrm{H}_{2} \mathrm{O}$. This would account for a difference of about $25 \%$ of externally measured volume changes in these animals with RIP calibrated at PEEP $5 \mathrm{~cm} \mathrm{H}_{2} \mathrm{O}$ (incremental) and comparing $V \mathrm{~T}_{\mathrm{i}, \text { VENT }}$ and $V_{\mathrm{T}_{\mathrm{i}, \mathrm{RIP}}}$ at PEEP 5 and $25 \mathrm{~cm} \mathrm{H}_{2} \mathrm{O}$.

A further explanation for the varying precision may be found in interindividual changes in thoracic shape with

Table 4. Values for $K$ and $M$ obtained with QDC in healthy animals, at various PEEP steps.

\begin{tabular}{lcc}
\hline & $\begin{array}{c}K \text { mean } \\
\text { (SD) }\end{array}$ & $\begin{array}{c}M \text { mean } \\
(\mathrm{SD})(\mathrm{ml})\end{array}$ \\
\hline $\begin{array}{l}\text { Healthy PEEP 5 } \\
\text { (incremental PEEP) }\end{array}$ & $1.03(0.45)$ & $1.74(0.31)$ \\
$\begin{array}{c}\text { Healthy PEEP 10 } \\
\text { (incremental PEEP) }\end{array}$ & $0.97(0.41)$ & $1.83(0.44)$ \\
$\begin{array}{c}\text { Healthy PEEP 15 } \\
\quad \text { (incremental PEEP) }\end{array}$ & $0.93(0.19)$ & $1.88(0.41)$ \\
$\begin{array}{c}\text { Healthy PEEP 20 } \\
\text { (maximal PEEP) }\end{array}$ & $1.15(0.70)$ & $1.75(0.47)$ \\
$\begin{array}{c}\text { Healthy PEEP 15 } \\
\quad \text { (decremental PEEP) }\end{array}$ & $1.09(0.38)$ & $1.85(0.47)$ \\
$\begin{array}{c}\text { Healthy PEEP 10 } \\
\quad(\text { decremental PEEP) }\end{array}$ & $1.09(0.17)$ & $1.75(0.31)$ \\
$\begin{array}{c}\text { Healthy PEEP 5 } \\
\text { (decremental PEEP) }\end{array}$ & $1.15(0.69)$ & $1.75(0.47)$ \\
\hline
\end{tabular}

All differences NS changing PEEP. With increasing lung volume, the saggital shape of the thorax changes; in the upper portion of the ribcage lateral displacement is minimal with inspiration ('pump handle' motion) whereas ventral displacement is minimal in the lower portion of the rib cage ('bucket handle' motion) [29]. We placed the thoracic belt at the caudal part of the chest. In humans, in this region chest expansion with inspiration is mainly in the frontal plane rather than in the transverse plane, leading to a change in cross-sectional shape. It has been shown that inductive sensors are sensitive to both cross-sectional perimeter and area variations, and that (depending on the deformation) these sensors measure either perimeter or area [30]. Watson et al. have demonstrated a linear relationship between RIP output and cross-sectional area [31]. However, the relation between self-inductance of the RIP coils and cross-sectional area varies with ellipticity or shape of the cross-section [32].

\section{Conclusion}

Our results suggest that when RIP is used during mechanical ventilation, the most reliable results are obtained when measurements are preceded by a calibration in comparable pulmonary conditions to the measurement period. In practice, this may not always be feasible and practical. When RIP calibration is omitted, a fixed weight factor $K$ may be used which may, however, result in less accuracy. Our study demonstrated an unpredictable dependence of PEEP. Despite this limitation, RIP is a measurement method comparable to other techniques of lung volume change measurement. Measurement errors should be taken into account with interpretation of small volume changes.

When lung conditions change, RIP partially loses its accuracy; during mechanical ventilation RIP should not be used as a device to monitor lung volume changes during a prolonged period of time. The potential advantage of the technique is its use during relatively short procedures, such as lung volume recruitment and subsequent decrease in airway pressures [11]. A device that provides clinicians with integrated information on ventilator settings and dependent physiologic variables may prove to be a valuable asset [16], but this remains to be demonstrated in clinical tests.

Table 5. Relative measurement errors of other measurement devices. RIP accuracy obtained with QDC performed at $10 \mathrm{~cm} \mathrm{H}_{2} \mathrm{O}$ incremental PEEP and in the same disease state as the measurements were performed is given (table 3 ).

\begin{tabular}{|c|c|c|c|c|c|}
\hline Device & Experimental model & Bias $(\%)$ & $2 \mathrm{SD}(\%)$ & Measures & Reference \\
\hline Siemens Servo 300 & Intubated children & 18 & 12 & $V_{\mathrm{T}}$ & [33] \\
\hline Respiratory inductive plethysmograpy & Animal model & -2 & 9 & $V_{\mathrm{T}} /$ relative EELV changes & Present study \\
\hline Hot wire anemometer (Florian) & In vitro lung model & 6.3 & 5 & $V_{\mathrm{T}}$ & {$[34]$} \\
\hline Babylog 8000 & In vitro lung model & -5.5 & 3 & $V_{\mathrm{T}}$ & {$[35]$} \\
\hline
\end{tabular}




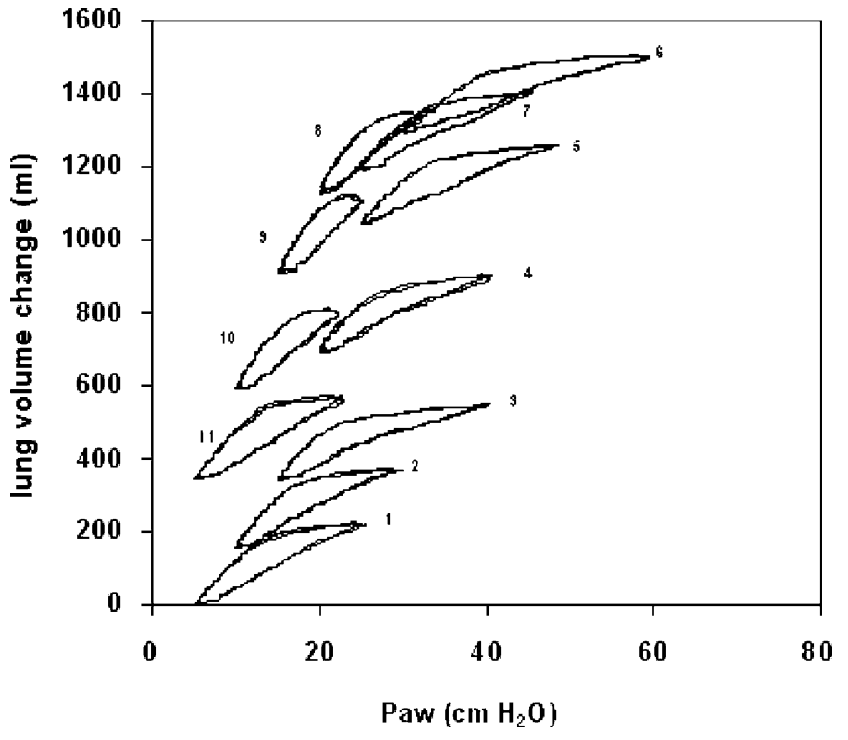

Figure 4. Lung volume change (calibrated RIP signal) with each PEEP step in one piglet at lavage target, relative to lung volume at initial PEEP of $5 \mathrm{~cm} \mathrm{H}_{2} \mathrm{O}$. Numbers indicate successive changes in PEEP. Step 1 to 6: incremental PEEP changes from 5 to $30 \mathrm{~cm} \mathrm{H}_{2} \mathrm{O}$, step 6 to 11: decremental PEEP changes from 30 to $5 \mathrm{~cm} \mathrm{H}_{2} \mathrm{O}$. Each dynamic pressure volume curve is constructed of two subsequent breaths following 5 minutes of undisturbed mechanical ventilation. Respiratory inductive plethysmograph calibrated at $20 \mathrm{~cm} \mathrm{H}_{2} \mathrm{O}$ decremental PEEP. $P_{\text {aw }}$ : airway pressure

\section{Acknowledgements}

From the Erasmus Medical Center Rotterdam (department of anaesthesiology) we thank S. Krabbendam for expert technical assistance and Laraine Visser-Isles for English language editing. We are grateful to Prof. Dr J. W. R. Twisk for his statistical advice.

\section{References}

[1] Dreyfuss, D. and Saumon, G., 1998, Ventilator-induced lung injury: lessons from experimental studies. American Journal of Respiratory and Critical Care Medicine, 157, 294-323.

[2] Dreyfuss, D., Soler, P., Basset, G. and Saumon, G., 1998, High inflation pressure pulmonary edema. Respective effects of high airway pressure, high tidal volume, and positive end-expiratory pressure. American Review of Respiratory Disease, 137, 1159-1164.

[3] Taskar, V., John, J., Evander, E., Robertson, B. and Jonson, B., 1997, Surfactant dysfunction makes lungs vulnerable to repetitive collapse and reexpansion. American Journal of Respiratory and Critical Care Medicine, 155, 313-320.

[4] McCulloch, P.R., Forkert, P.G. and Froese, A.B., 1998, Lung volume maintenance prevents lung injury during high frequency oscillatory ventilation in surfactant-deficient rabbits. American Review of Respiratory Disease, 137, 1185-1192.
[5] Amato, M.B., Barbas, C.S., Medeiros, D.M., Magaldi, R.B., Schettino, G.P., Lorenzi-Filho, G., Kairalla, R.A., Deheinzelin, D., Munoz, C., Oliveira, R., Takagaki, T.Y. and Carvalho, C.R., 1998, Effect of a protective-ventilation strategy on mortality in the acute respiratory distress syndrome. New England Journal of Medicine, 338, $347-354$.

[6] Rimensberger, P.C., Pache, J.C., McKerlie, C., Frndova, H. and Cox, P.N., 2000, Lung recruitment and lung volume maintenance: a strategy for improving oxygenation and preventing lung injury during both conventional mechanical ventilation and high-frequency oscillation. Intensive Care Medicine, 26, 745-755.

[7] Sackner, M.A., Watson, H., Belsito, A.S., Feinerman, D., Suarez, M., Gonzalez, G., Bizousky, F. and Krieger B., 1989, Calibration of respiratory inductive plethysmograph during natural breathing. Journal of Applied Physiology, 66, 410-420.

[8] Stromberg, N.O., Dahlback, G.O. and Gustafsson, P.M., 1993, Evaluation of various models for respiratory inductance plethysmography calibration. Journal of Applied Physiology, 74, 1206-1211.

[9] Adams, J.A., Zabaleta, I.A., Stroh, D., Johnson, P. and Sackner, M.A., 1993, Tidal volume measurements in newborns using respiratory inductive plethysmography. American Review of Respiratory Disease, 148, 585-588.

[10] Valta, P., Takala, J., Foster, R., Weissman, C. and Kinney, J.M., 1992, Evaluation of respiratory inductive plethysmography in the measurement of breathing pattern and PEEP-induced changes in lung volume. Chest, 102, 234-238.

[11] Brazelton III, T.B., Watson, K.F., Murphy, M., Al Khadra, E., Thompson, J.E. and Arnold, J.H., 2001, Identification of optimal lung volume during high-frequency oscillatory ventilation using respiratory inductive plethysmography. Critical Care Medicine, 29, 2349-2359.

[12] Weber, K., Courtney, S.E., Pyon, K.H., Chang, G.Y., Pandit, P.B. and Habib, R.H., 2000, Detecting lung overdistention in newborns treated with high-frequency oscillatory ventilation. Journal of Applied Physiology, 89, 364-372.

[13] Gothberg, S., Parker, T.A., Griebel, J., Abman, S.H. and Kinsella, J.P., 2001, Lung volume recruitment in lambs during high-frequency oscillatory ventilation using respiratory inductive plethysmography. Pediatric Research, 49, 38-44.

[14] Leino, K., Nunes, S., Valta, P. and Takala, J., 2001, Validation of a new respiratory inductive plethysmograph. Acta Anaesthesiologica Scandinavica, 45, 104-111.

[15] Neumann, P., Zinserling, J., Haase, C., Sydow, M. and Burchardi, H., 1998, Evaluation of respiratory inductive plethysmography in controlled ventilation: measurement of tidal volume and PEEPinduced changes of end-expiratory lung volume. Chest, 113, 443-451.

[16] Markhorst, D.G., Genderingen, H.R., Leenhoven, T. and van Vught, A.J., 2003, A system for integrated measurement of ventilator settings, lung volume change and blood gases during high-frequency oscillatory ventilation. Journal of Medical Engineering \& Technology, 27, $128-$ 132.

[17] Cannon, M.L., Cornell, J., Tripp-Hamel, D.S., Gentile, M.A., Hubble, C.L., Meliones, J.N. and Cheifetz, I.M., 2000, Tidal volumes for ventilated infants should be determined with a pneumotachometer placed at the endotracheal tube. American Journal of Respiratory and Critical Care Medicine, 162, 2109-2112.

[18] Lachmann, B., Robertson, B. and Vogel, J., 1980, In vivo lung lavage as an experimental model of the respiratory distress syndrome. Acta Anaesthesiologica Scandinavica, 24, 231-236.

[19] Vazquez de Anda, G.F., Lachmann, R.A., Gommers, D., Verbrugge, S.J., Haitsma, J. and Lachmann, B., 2001, Treatment of ventilationinduced lung injury with exogenous surfactant. Intensive Care Medicine, 27, 559-565.

[20] Poole, K.A., Thompson, J.R., Hallinan, H.M. and Beardsmore, C.S., 2000, Respiratory inductance plethysmography in healthy infants: a comparison of three calibration methods. European Respiratory Journal, 16, 1084-1090. 
[21] Banzett, R.B., Mahan, S.T., Garner, D.M., Brughera, A. and Loring, S.H., 1995, A simple and reliable method to calibrate respiratory magnetometers and Respitrace. Journal of Applied Physiology, 79, $2169-2176$

[22] Bland, J. and Altman, D.G., 1986, Statistical methods for assessing agreement between two methods of clinical measurement. Lancet, $\mathbf{1}$, $307-310$.

[23] Albaiceta, G.M., Piacentini, E., Villagra, A., Lopez-Aguilar, J., Taboada, F. and Blanch, L., 2003, Application of continuous positive airway pressure to trace static pressure-volume curves of the respiratory system. Critical Care Medicine, 31, 2514-2519.

[24] Werchowski, J.L., Sanders, M.H., Costantino, J.P., Sciurba, F.C. and Rogers, R.M., 1990, Inductance plethysmography measurement of CPAP-induced changes in end-expiratory lung volume. Journal of Applied Physiology, 68, 1732-1738.

[25] Gattinoni, L., Pelosi, P., Suter, P.M., Pedoto, A., Vercesi, P. and Lissoni, A., 1998, Acute respiratory distress syndrome caused by pulmonary and extrapulmonary disease. Different syndromes? American Journal of Respiratory and Critical Care Medicine, 158, 3-11.

[26] Manczur, T., Greenough, A., Hooper, R., Allen, K., Latham, S., Price, J.F., Rafferty, G.F., 1999, Tidal breathing parameters in young children: comparison of measurement by respiratory inductance plethysmography to a facemask pneumotachograph system. Pediatric Pulmonology, 28, 436-441.

[27] de Groote, A., Paiva, M. and Verbandt, Y., 2001, Mathematical assessment of qualitative calibration for respiratory inductive plethysmography. Journal of Applied Physiology, 90, 1025-1030.
[28] Grotjohan, H.P. and van der Heijde, R.M.J.L., 1992, Experimental models of the respiratory distress syndrome. Lavage and oleic acid. PhD Thesis, Erasmus University, Rotterdam, The Netherlands.

[29] de Troyer, A.D., 1997, The respiratory muscles. In: R.G. Crystal, and J.B. West (Eds) The lung: scientific foundations (Philadelphia: Lippincott-Raven Publishers).

[30] de Groote, A., Verbandt, Y., Paiva, M. and Mathys, P., 2000, Measurement of thoracoabdominal asynchrony: importance of sensor sensitivity to cross section deformations. Journal of Applied Physiology, 88, 1295-1302.

[31] Watson, H.L., Poole, D.A. and Sackner, M.A., 1998, Accuracy of respiratory inductive plethysmographic cross-sectional areas. Journal of Applied Physiology, 65, 306-308.

[32] Martinot-Lagarde P, Sartene R, Mathieu M, Durand G. 1988, What does inductance plethysmography really measure? Journal of Applied Physiology, 64, 1749-1756.

[33] Castle, R.A., Dunne, C.J., Mok, Q., Wade, A.M. and Stocks, J., 2002, Accuracy of displayed values of tidal volume in the pediatric intensive care unit. Critical Care Medicine, 30, 2566-2574.

[34] Scalfaro, P., Pillow, J.J., Sly, P.D. and Cotting, J., 2001, Reliable tidal volume estimates at the airway opening with an infant monitor during high-frequency oscillatory ventilation. Critical Care Medicine, 29, $1925-1930$.

[35] Roske, K., Foitzik, B., Wauer, R.R. and Schmalisch, G., 1998, Accuracy of volume measurements in mechanically ventilated newborns: a comparative study of commercial devices. Journal of Clinical Monitoring and Computing, 14, 413-420. 